\title{
$36 \mathrm{~h}$ fasting of young men influences adipose tissue DNA methylation of LEP and $A D I P O Q$ in a birth weight-dependent manner
}

Line Hjort ${ }^{1,2,3^{*}}$, Sine W. Jørgensen ${ }^{1,4}$, Linn Gillberg ${ }^{1}$, Elin Hall ${ }^{5}$, Charlotte Brøns ${ }^{1}$, Jan Frystyk ${ }^{6}$, Allan A. Vaag ${ }^{1,7}$ and Charlotte Ling ${ }^{5^{*}}$

\begin{abstract}
Background: Subjects born with low birth weight (LBW) display a more energy-conserving response to fasting compared with normal birth weight (NBW) subjects. However, the molecular mechanisms explaining these metabolic differences remain unknown. Environmental influences may dynamically affect epigenetic marks, also in postnatal life. Here, we aimed to study the effects of short-term fasting on leptin (LEP) and adiponectin (ADIPOQ) DNA methylation and gene expression in subcutaneous adipose tissue (SAT) from subjects with LBW and NBW.

Methods: Twenty-one young LBW men and 18 matched NBW controls were studied during $36 \mathrm{~h}$ fasting. Eight subjects from each group completed a control study (overnight fast). We analyzed SAT LEP and ADIPOQ methylation (Epityper MassARRAY), gene expression (q-PCR), and adipokine plasma levels.

Results: After overnight fast (control study), LEP and ADIPOQ DNA methylation levels were higher in LBW compared to those in NBW subjects $(p \leq 0.03)$ and increased with $36 \mathrm{~h}$ fasting in NBW subjects only $(p \leq 0.06)$. Both $L E P$ and ADIPOQ methylation levels were positively associated with total body fat percentage $(p \leq 0.05)$. Plasma leptin levels were higher in LBW versus NBW subjects after overnight fasting $(p=0.04)$ and decreased more than threefold in both groups after $36 \mathrm{~h}$ fasting $(p \leq 0.0001)$.

Conclusions: This is the first study to demonstrate that fasting induces changes in DNA methylation. This was shown in LEP and ADIPOQ promoters in SAT among NBW but not LBW subjects. The altered epigenetic flexibility in LBW subjects might contribute to their differential response to fasting, adipokine levels, and increased risk of metabolic disease.
\end{abstract}

Keywords: Epigenetics, Fasting, Type 2 diabetes, Low birth weight, Adipose tissue, Leptin, Adiponectin

\section{Background}

DNA methylation is the most studied epigenetic feature and was initially considered to be mitotically stable. However, today we experience an increasing understanding of environmental regulation of DNA methylation in adult life, and recent studies have shown that ageing [1-3], exercise

\footnotetext{
* Correspondence: line.hjort@regionh.dk; charlotte.ling@med.lu.se 'Department of Endocrinology (Diabetes and Metabolism), Rigshospitalet, section 7652, Tagensvej 20, DK-2200 Copenhagen N, Denmark

${ }^{5}$ Epigenetics and Diabetes and Islet Cell Exocytosis, Department of Clinical

Sciences, Lund University Diabetes Centre, Lund University, CRC, Jan

Waldentröms gata 35, SE-20502 Malmö, Sweden

Full list of author information is available at the end of the article
}

$[4,5]$, and dietary factors [6-9] can alter site-specific DNA methylation in humans, across different tissues. Epigenetic modifications have further been associated with differential gene expression and altered metabolism in key diabetic tissues, including adipose tissue [4, 10-12].

Adipose tissue regulates energy homeostasis by storing lipids and secreting adipokines, and dysregulation of adipokine secretion has been shown to be directly involved in the pathophysiology of the metabolic syndrome [13, 14]. The most important adipokines include leptin, a key hormone regulating satiety that show a high correlation between adipose tissue mass and plasma 
levels [15] and adiponectin, an important regulator of glucose and lipid metabolism, which, in spite of its exclusive secretion from adipose tissue, shows a negative correlation with visceral adiposity [16].

Type 2 diabetes (T2D) and obesity are complex and multi-factorial diseases with an etiology dependent upon both genetic and environmental factors, where also the prenatal environment may play an important role [17]. The establishment of epigenetic modifications during fetal development is dependent on maternal lifestyle [18], placental function, and nutrient supply [19] and may link an adverse prenatal environment with higher risk of developing metabolic diseases in postnatal life [20,21]. Being born with low birth weight (LBW) has been confirmed in several human studies to be associated with increased risk of developing insulin resistance and T2D in adult life [22-24]. In this regard, several studies have reported alterations of epigenetic patterns and plasticity in human tissues that are relevant to metabolic diseases in subjects born at term with a LBW compared to normal birth weight (NBW) subjects [6, 8, 9, 25].

LBW individuals have been characterized with increased total [23] and abdominal [6] fat mass in early adulthood compared to NBW individuals. Previously, we have found that when exposed to high-fat overfeeding, young LBW men respond with less increase in fasting plasma leptin (p-leptin) levels compared to NBW subjects [26]. This suggests an impaired regulation of leptin secretion and/or expression among LBW subjects. Additionally, we recently showed that LBW subjects display a more energy-conserving response to fasting compared with NBW subjects [27]. However, whether adipokine dysregulation is involved in development of metabolic diseases among LBW subjects and, importantly by which mechanisms, remains to be elucidated.

To our knowledge, the effects of fasting on DNA methylation have not been examined previously. In the present study, we investigated whether DNA methylation and expression of $L E P$ and $A D I P O Q$ were affected by $36 \mathrm{~h}$ fasting, in subcutaneous adipose tissue (SAT) from young, healthy NBW and LBW men.

\section{Methods}

\section{Study design}

As previously published [27], $21 \mathrm{LBW}$ and 18 NBW subjects were recruited from the Danish National Birth Registry according to LBW (birth weight $\leq 10$ th percentile) or NBW (50th percentile $\leq$ birth weight $\leq 75$ th percentile). All participants were born at term (week 39-41) and were matched as healthy, non-diabetic, young males, with no history of diabetes in two generations and with a BMI $<30 \mathrm{~kg} / \mathrm{m}^{2}$. All participants were subjected to $36 \mathrm{~h}$ fasting, and after 8-16 weeks, $7 \mathrm{LBW}$ and $6 \mathrm{NBW}$ subjects were examined again during a control study, conducted through a $36-\mathrm{h}$ period where the subjects received a diet equal to the standardization meals, and where biopsies were excised after an overnight (12 h) fast. Furthermore, $1 \mathrm{LBW}$ and 2 NBW subjects returned after 3 days of standardization by control diet, only to participate by collection of overnight fasting samples $(12 \mathrm{~h})$ and tissue biopsies as described below. Thus, control study samples were obtained after an overnight fast from a total of $8 \mathrm{LBW}$ and $8 \mathrm{NBW}$ subjects who all also participated in the 36-h fasting study.

For $72 \mathrm{~h}$ prior to the fasting or control study interventions, the participants received a control diet of precooked meals to achieve standardization of energy intake (10 MJ per day, 50\% carbohydrate, 35\% fat, $15 \%$ protein). In addition the participants were not allowed to perform exercise or consume alcohol or soft drinks in these 3 days. During both the fasting and control study, the participants were allowed ad libitum water.

\section{Clinical examinations}

The fasting intervention study and the control study were performed with identical study settings and activities, carried out over 3 days (Fig. 1). The participants arrived at Steno Diabetes Center at 7.30 p.m., where they received a meal. In the fasting study, finishing of the meal marked the beginning of the fasting period. The next day (day 1), a catheter was placed in the subjects' left arm and blood sampling began at 8.00 a.m. During day 1 , anthropometric measurements of weight, height, BMI, and waist-hip ratio were obtained and dual-energy X-ray absorptiometry (DXA) scanning (Hologic Discovery QDR Series) was performed for determination of body composition. Furthermore, the participants had two periods of light exercise to avoid inactivity. On day 2, after $36 \mathrm{~h}$ fasting, between 7.00 and 7.30 a.m., abdominal SAT biopsies were obtained using a Bergström needle under suction and under local anesthesia by Xylocain (AstraZeneca). Immediately biopsies were frozen in liquid nitrogen and stored at $-80^{\circ} \mathrm{C}$. At 8.00 a.m., an Intravenous Glucose Tolerance Test (IVGTT) was initiated (ending the fasting period), and at 11.00 a.m., the participant received a standardized test meal, which should be consumed within $15 \mathrm{~min}$.

In brief, LBW subjects were characterized by a shorter height $(p=0.01)$ and lower lean body mass $(p<0.03)$, but with similar fat mass, total body fat percentage (BF\%), BMI, and metabolic markers as NBW subjects. In both groups, the fasting intervention increased free fatty acid levels and reduced the clearance of p-glucose during the IVGTT, most likely due to development of peripheral insulin resistance as a consequence of fasting. Furthermore, we found that LBW subjects had a more pronounced decrease in s-insulin and triglyceride levels and exhibited a decrease of the total rate of energy 


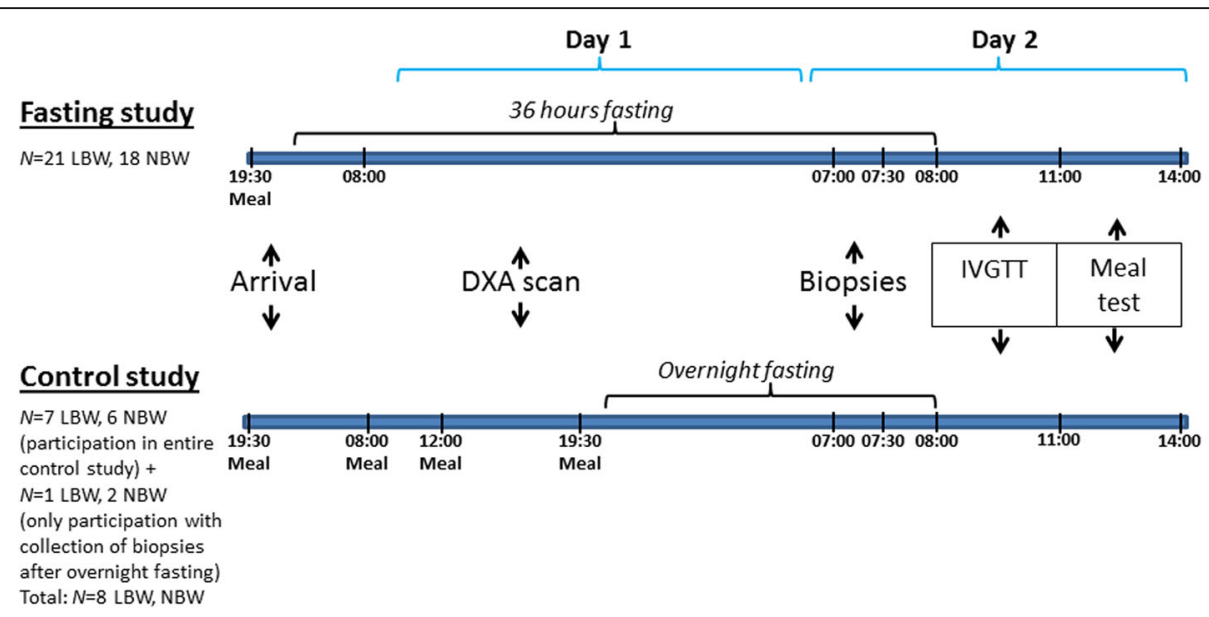

Fig. 1 Study design. Overview of the study activities and time periods of fasting shown in both the fasting study and the control study. 21 LBW and 18 NBW men participated in the 36-h fasting study intervention. A subset of 7 LBW and 6 NBW men from the 36-h fasting study also participated in the control study intervention. Further 1 LBW and 2 NBW men also participated in the control study only with biopsy collections. Abbreviations: LBW low birth weight, NBW normal birth weight, DXA scan dual-energy X-ray absorptiometry scan, IVGTT intravenous glucose tolerance test

expenditure during fasting which increased among NBW subjects. These data have previously been reported in more detail [27] and are summarized in Table 1.

\section{Intravenous glucose tolerance test}

For evaluation of in vivo beta cell function, an intravenous glucose tolerance test (IVGTT) was conducted. A dose of $0.3 \mathrm{~g}$ glucose $/ \mathrm{kg}$ body weight was infused and caused a first-phase insulin response (FPIR), which peaked within 2$5 \mathrm{~min}$ and lasted approximately $10 \mathrm{~min}$. Twenty minutes after administration of the glucose dose, an IV insulin bolus of $0.02 \mathrm{IU}$ insulin $/ \mathrm{kg}$ (Actrapid ${ }^{\circ}$, Novo Nordisk) was infused. The IVGTT assessment and the calculations of insulin sensitivity have been described in detail previously [27].

\section{Blood sampling and biomarker analysis}

All plasma samples were immediately distributed into tubes, placed on ice, and centrifuged at $3000 \mathrm{rpm}$ for 15 min (Eppendorf Centrifuge 5810R, Eppendorf AG, Hamburg, Germany). Plasma and serum were obtained and stored at $-80{ }^{\circ} \mathrm{C}$ for later analysis. Blood sampling for plasma leptin and adiponectin (p-leptin, $\mathrm{p}$-adiponectin) was performed immediately after 12 and $36 \mathrm{~h}$ of both the fasting and control study, $3 \mathrm{~h}$ after initiation of the IVGTT, and $3 \mathrm{~h}$ after the meal test (Fig. 1).

Plasma adiponectin and leptin were determined by validated, in-house, monoclonal immunoassays, based on commercial reagents from Bio-Techne (Abingdon, UK). The assays were performed without any pre-treatment of samples prior to assay apart from appropriate dilution. Adiponectin was determined using MAB 10651 for coating and BAM 1065 for detection, leptin was determined using MAB 398 for coating and BAM 398 for detection. Recombinant proteins served as assay calibrators. All samples were assayed in duplicates, with intra-assay coefficients of variation $(\mathrm{CV})$ of unknown samples $<5 \%$ and inter-assay CVs of control samples $<10 \%[28,29]$. All concentrations below the lower limit of detection (the non-specific binding control plus three standard deviations (SD)) were arbitrarily set at $0.1 \mu \mathrm{g} / \mathrm{L}$ for $\mathrm{p}$-leptin, and $0.1 \mathrm{mg} / \mathrm{L}$ for p-adiponectin (total).

\section{DNA methylation analyses}

Genomic DNA was extracted from SAT biopsies using the QIAamp DNA Mini Kit (Qiagen, Valencia, CA, USA). To quantify DNA methylation of $L E P$ and ADI$P O Q$, Sequenom's MassARRAY EpiTYPER protocol was applied (Sequenom, San Diego, CA, USA). Assays were designed using EpiDesigner (Sequenom). The human LEP promoter contains a CpG island that is associated with demethylation during adipocyte differentiation [30]; hence, we aimed to study DNA methylation in this region. Two EpiTYPER assays were designed to cover the LEP proximal promoter region, including $57 \mathrm{CpG}$ sites. Due to either low or high mass of the DNA cleavage lengths, in total $39 \mathrm{CpG}$ sites generated measurable DNA methylation data (Fig. 2a). A proximal ADIPOQ promoter region has been shown to be sufficient for basal transcriptional activity [31], and additionally, a distal enhancer region has also been shown to affect adiponectin promoter activity [32]. Hence, one assay was designed in the enhancer region and one assay in the proximal promoter, covering in total 10 measurable CpG sites (Fig. 2b). Primer sequences are shown in Additional file 1: Table S1. Due to base-specific cleavage, several CpG sites were analyzed as units, as indicated in Fig. 2.

Genomic DNA (400 ng) from adipose tissue was bisulfite converted using the high-throughput EZ-96 DNA 
Table 1 Clinical characteristics of the study participants

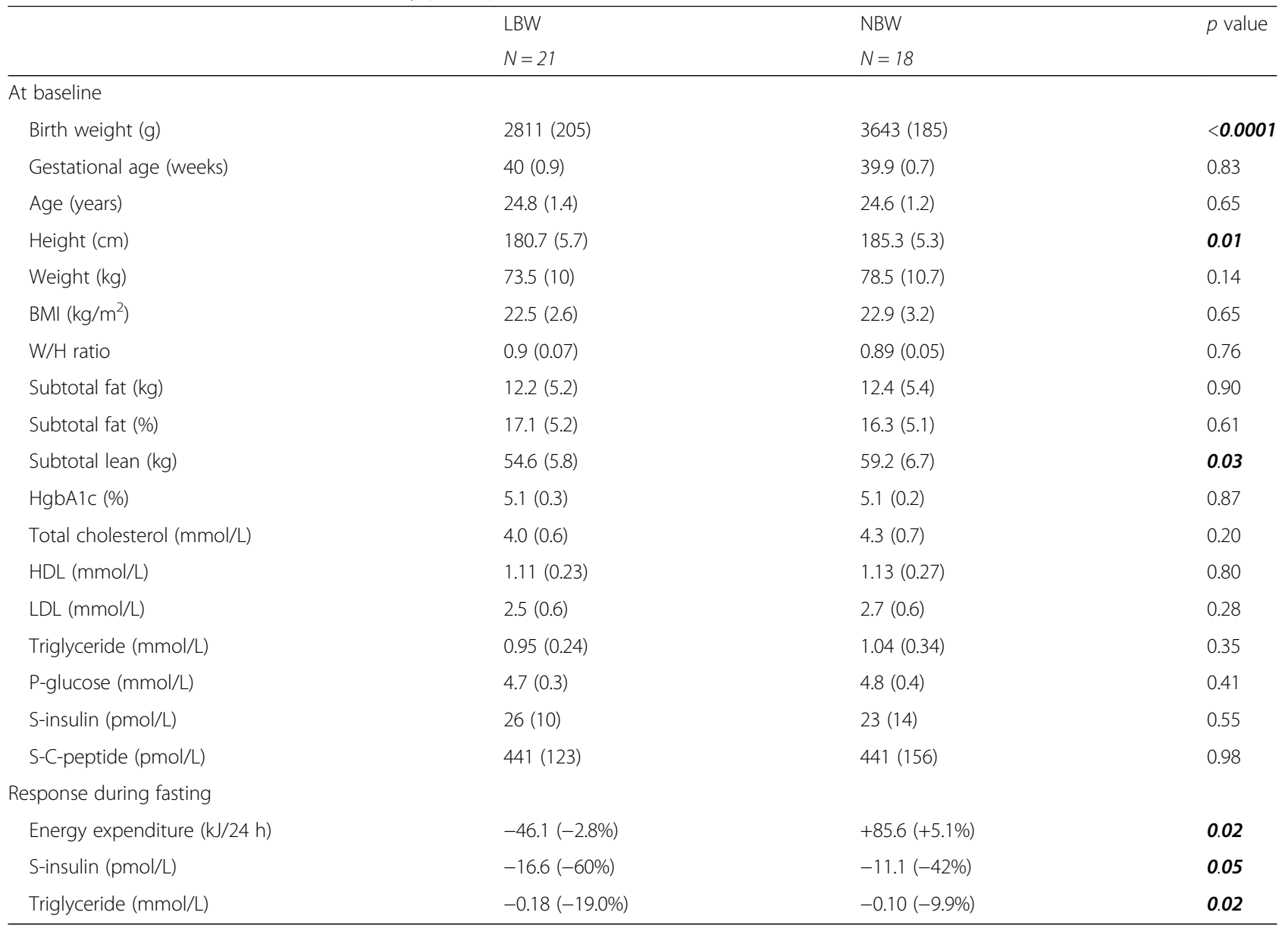

Data are means (SD). $p$ values $<0.05$ are bold. Lipids, glucose and insulin/C-peptide were measured at $8.00 \mathrm{AM}$ on day 1 , after $12 \mathrm{~h}$ of fasting (in the fasting study). $\mathrm{HgbA1c}$ was measured before the standardization period. Change in energy expenditure was calculated from after $12 \mathrm{~h}$ fasting until $31 \mathrm{~h}$ fasting. Changes in insulin and triglyceride during fasting were calculated from after $12 \mathrm{~h}$ fasting until 34 and $36 \mathrm{~h}$ fasting, respectively. These results have previously been reported [27] $B M I$ body mass index, W/H ratio waist-hip ratio, Subtotal without the head, Lean without fat and bone

Methylation Kit (ZYMO Research, Orange, CA, USA). Bisulfite-specific primers (Additional file 1: Table S1) were used to generate PCR amplicons. The PCR amplicons were then processed using the MassCleave (hMC) kit. The reverse transcribed cleavage products were dispensed onto a 384 element SpectroCHIP bioarray and using the MassARRAY mass spectrometer (Sequenom), mass spectra were obtained and DNA methylation ratios were analyzed by the EpiTYPER software v.1.0.1 (Sequenom).

\section{Gene expression}

The miRNeasy Mini Kit (Qiagen) was used for total RNA extraction. cDNA synthesis was performed with the QuantiTect Reverse Transcription Kit (Qiagen). Messenger RNA (mRNA) expression of $L E P, A D I P O Q$ and the reference gene cyclophilin A (PPIA) was measured by quantitative real-time PCR (q-PCR) using the ABI PRISM 7900HT Sequence Detection System (Applied Biosystems) and assays-on-design for LEP (Hs00174877_m1*, FAMlabelled), ADIPOQ (Hs00605917_m1*, FAM-labelled), and
PPIA (43263116E, VIC-labelled) (all Applied Biosystems). The standard curve principal was applied for gene expression quantification and samples were normalized to PPIA. Birth weight and fasting did not affect the expression of PPIA (Additional file 2: Figure S1).

\section{Statistical methodology}

Analyses for parametric data were performed using the paired and unpaired Student $t$ test and analyses of nonparametrically distributed data were performed using the Wilcoxon test for paired data and the Mann-Whitney $U$-test for unpaired data. Correlation analyses were performed using the Pearson correlation test for parametric data and Spearman rank correlation test for nonparametric data. A mixed effects model was applied to analyze the repeated measurements of p-leptin and padiponectin at all four time points of collection under the choice of an unstructured correlation model according to the structure of data, the distribution of the residual variances and the number of parameters involved. 


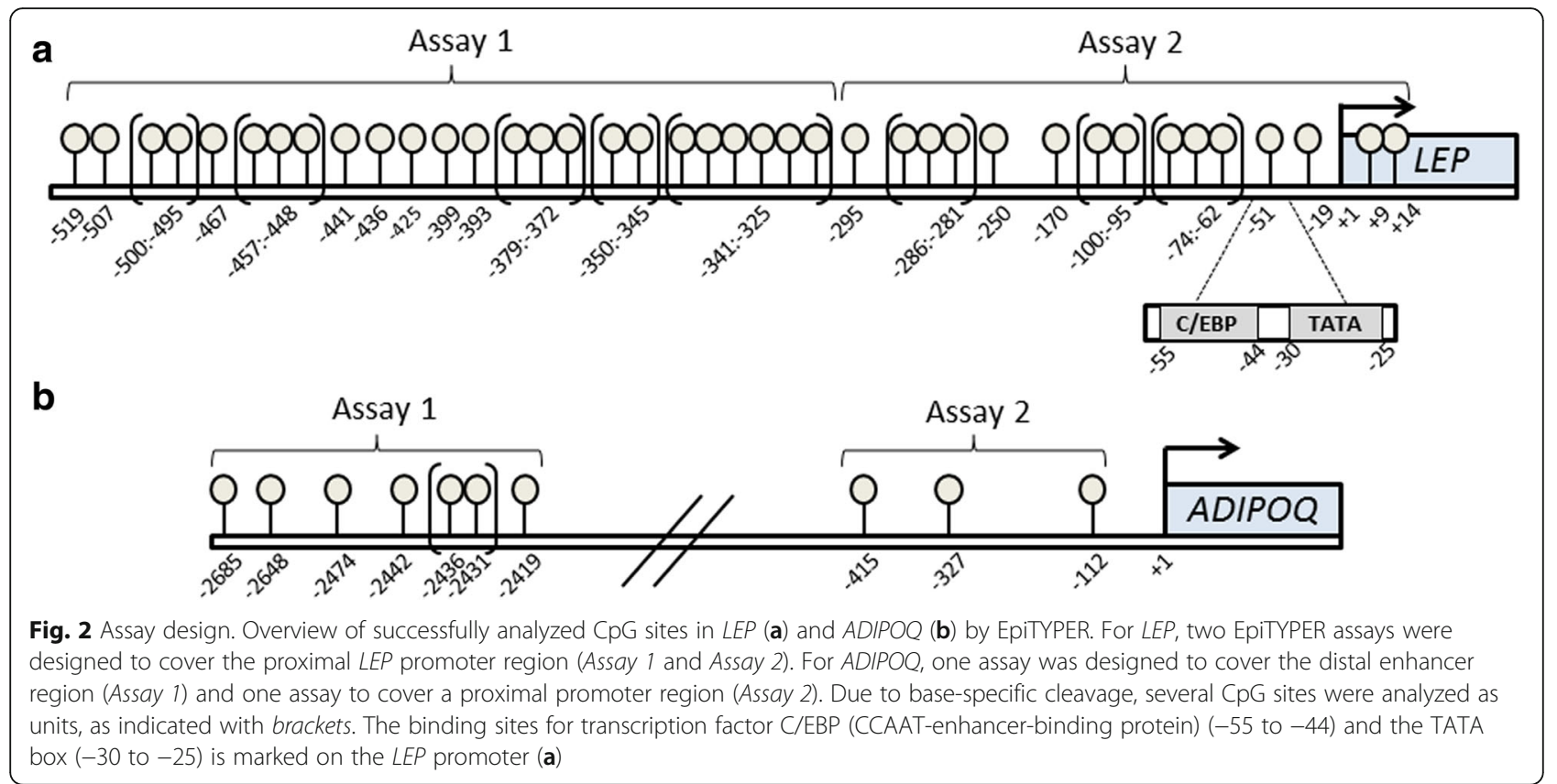

In the mixed effects model, the residuals of p-leptin were found to have a non-parametric distribution and $\log$ transformation of p-leptin levels was therefore performed. All statistical tests were performed at a significance level of $p \leq 0.05$, using SAS 9.4 software (SAS Institute Inc., USA).

\section{Results}

\section{Study subject characteristics}

Clinical characteristics of both birth weight groups during the 36-h fasting study have previously been described [27] and are shown in Table 1.

\section{Influence of fasting on LEP and ADIPOQ DNA methylation in SAT}

The degree of $L E P$ and $A D I P O Q$ DNA methylation was positively correlated between the different $\mathrm{CpG}$ sites within an assay, in each gene promoter (all $p \leq 0.04$, results not shown). We therefore performed statistical analysis of the average degree of DNA methylation across all sites within each assay (Figs. 2, 3, and 4) as well as for the individual CPG sites (Additional file 1: Tables S2, S3, S4, and S5).

Among NBW subjects, the average degree of DNA methylation increased significantly with $2.2 \%$ in the promoter of LEP (assay 2, $p=0.04$ ) and borderline significantly with $3.9 \%$ in $A D I P O Q$ (assay 2, $p=0.06$ ), after $36 \mathrm{~h}$ fasting compared to the control study $(N=8+8 \mathrm{NBW}$, paired analysis) (Fig. 3a, b). In addition, at the individual CpG sites, $L E P$ DNA methylation increased $\sim 5 \%$ with fasting at sites -51 and $-19(p=0.01, p=0.03)$, and decreased $2.3 \%$ at site $-250(p=0.007)$ (Additional file 1: Table S2).
For $A D I P O Q$, DNA methylation increased $5.4 \%$ with fasting at site -327 among the NBW subjects $(p=0.007)$ (Additional file 1: Table S3).

Among LBW subjects, on the contrary, no influence of fasting was observed in either $L E P$ or ADIPOQ DNA methylation degree $(N=8+8 \mathrm{LBW}$, paired analysis) (Fig. 3a, b, Additional file 1: Tables S2 and S3).

\section{Influence of birth weight on LEP and ADIPOQ DNA methylation in SAT}

In the control study, LBW subjects presented $1.8 \%$ higher average degree of $L E P$ promoter DNA methylation (assay $1, p=0.02$ ) and 3.3\% higher average degree of $A D I P O Q$ promoter DNA methylation (assay 2, $p=0.03$ ) compared to NBW subjects $(N=8 \mathrm{LBW}$ versus $8 \mathrm{NBW}$, unpaired analysis) (Fig. 4a). In addition, two individual LEP CpG sites $(-441,-393)$ displayed higher levels of methylation among LBW subjects (Additional file 1: Table S4). There were no differences in average or sitespecific DNA methylation of $L E P$ assay 2 or $A D I P O Q$ assay 1 between NBW and LBW subjects in the control study (Fig. 4a and Additional file 1: Tables S4 and S5).

After $36 \mathrm{~h}$ fasting, there were no differences in average degree of $L E P$ or ADIPOQ DNA methylation between the two birth weight groups $(N=20 \mathrm{LBW}$ versus 17 NBW, unpaired analysis) (Fig. 4b). Nevertheless, one LEP CpG site (-519) displayed higher DNA methylation in LBW subjects compared to NBW subjects and one LEP CpG unit (covering sites -74, -71, -62) displayed lower methylation degree in LBW subjects compared to NBW subjects, after fasting $(p=0.02, p=0.05$, Additional file 1: Table S4). 

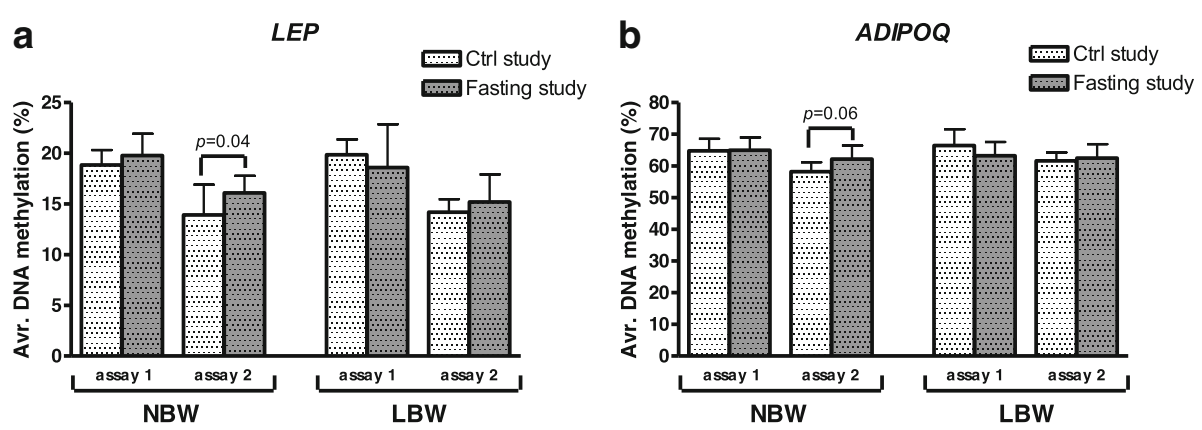

Fig. 3 Influence of fasting on DNA methylation of LEP (a) and ADIPOQ (b) in SAT from NBW and LBW men. Avr. average. N=8 LBW, 8 NBW. Comparisons by paired analyses between control and fasting study. Data are mean \pm SD

\section{LEP and ADIPOQ gene expression in SAT before and after fasting}

Gene expression of $L E P$ or $A D I P O Q$ did not differ between NBW and LBW subjects in either the control or fasting study (Fig. 5a, b). ADIPOQ expression levels increased significantly after fasting among LBW subjects $(p=0.04)$ but not among NBW subjects (Fig. 5c, d). No significant changes in LEP gene expression were found with fasting in either of the groups, but especially after fasting a large individual variation was observed in the LBW group (Fig. 5c, d).

\section{Adipokine plasma profiles before and after fasting}

At baseline, after the overnight fast of $12 \mathrm{~h}$, p-leptin levels were significantly higher among LBW subjects compared to the NBW group $(p=0.05)$. After $36 \mathrm{~h}$ fasting, both groups exhibited a more than threefold decrease of p-leptin levels $(p<0.0001)$ (Fig. 6a). When performing a mixed effects model of repeated measurements of p-leptin levels during the entire intervention study, the p-leptin effect over time was found to be significantly different between the groups $(p=0.01)$.

No difference was found in p-leptin levels between the groups after either the IVGTT or meal test, when examined by mixed effects models. In addition, these interventions did not appear to have any effect on pleptin levels, which remained low after the fasting challenge in both groups, though a slight and non-significant increase was observed in both groups (Fig. 6a).

The fasting intervention did not affect $\mathrm{p}$-adiponectin levels in either of the groups, and no differences were found in p-adiponectin levels between the groups at any of the time points during the intervention study (Fig. 6b).

\section{Associations between SAT LEP and ADIPOQ DNA methylation and mRNA expression}

Next, we investigated whether DNA methylation degree of the LEP and ADIPOQ promoter was associated to gene expression levels in SAT. A significant positive correlation was found between average LEP DNA methylation (assay 2) and mRNA expression only in the NBW group ( $p=$ 0.01 ) (Table 2). ADIPOQ DNA methylation in the proximal promoter (assay 2) was inversely associated with mRNA expression levels in both groups, with a borderline significance when groups were combined $(p=0.07)$ (Table 2).

\section{Associations between adiposity and SAT LEP and ADIPOQ DNA methylation or plasma levels}

Finally, we tested if $L E P$ and $A D I P O Q$ DNA methylation and/or gene expression in SAT were associated to

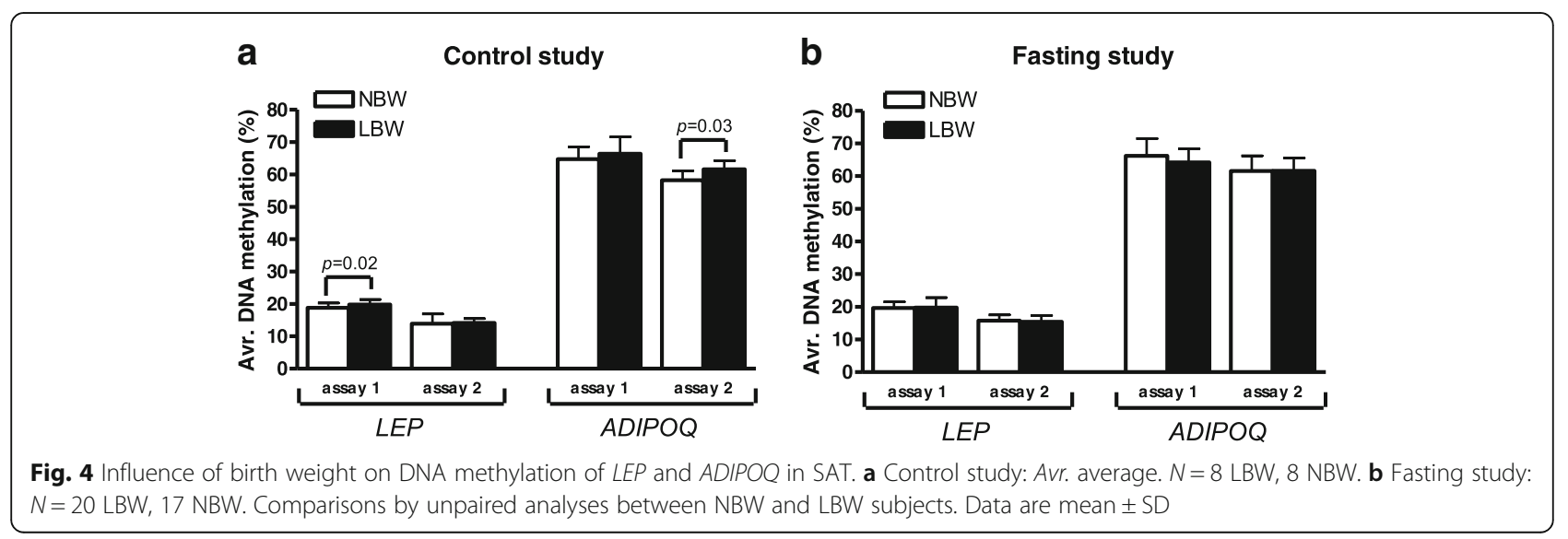



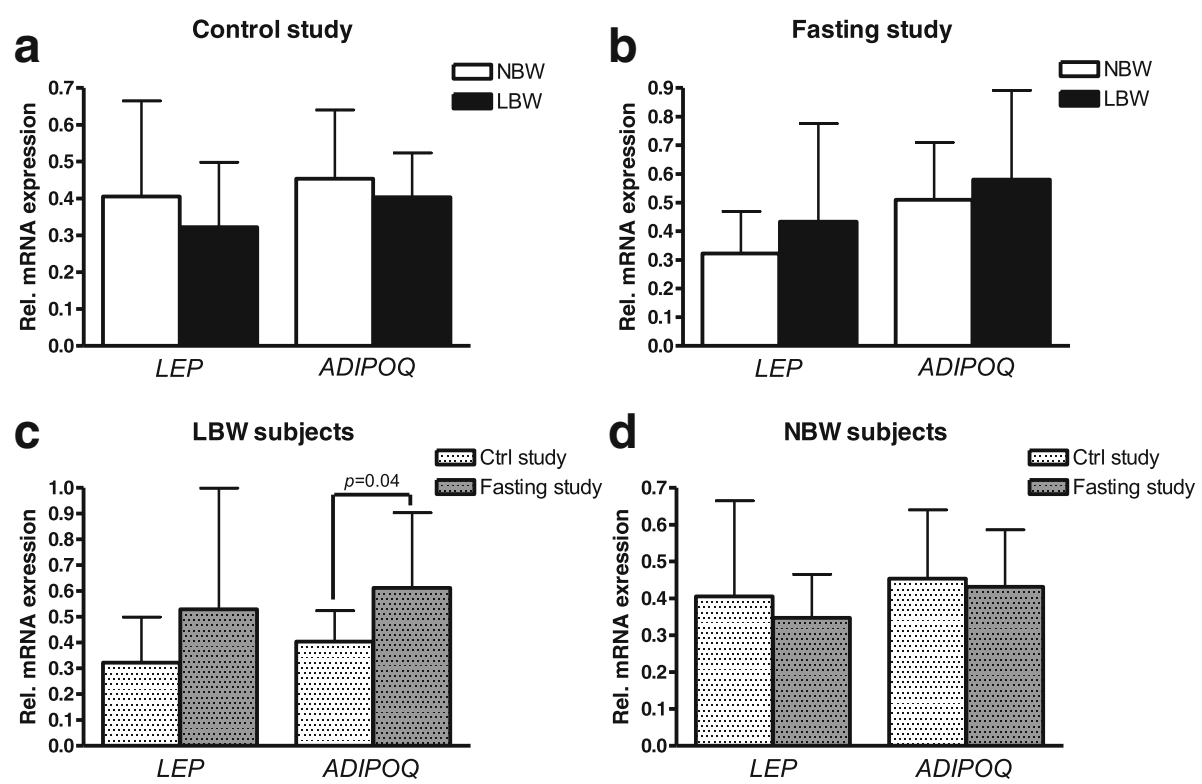

Fig. 5 Influence of birth weight $(\mathbf{a}, \mathbf{b})$ and fasting $(\mathbf{c}, \mathbf{d})$ on SAT LEP and ADIPOQ gene expression levels. Rel. relative. a Control study: N=8 LBW, 8 NBW. b Fasting study: $N=20$ LBW, 16 NBW, comparisons by unpaired analyses between NBW and LBW subjects. c, d N=8 LBW, 7 NBW,

comparisons by paired analyses between control and fasting study. Data are mean \pm SD

phenotype including the clinical characteristics of BMI, total $\mathrm{BF} \%$, and plasma adipokine levels. LEP (assay $1+2$ ) and $A D I P O Q$ (assay 1) DNA methylation was significantly positively associated with total $\mathrm{BF} \%(p<0.05)$ but not with BMI, when combining the groups $(n=37)$ (Table 2). When performing correlation analysis by birth weight group, only LBW subjects presented a positive association between LEP DNA methylation and total $\mathrm{BF} \%(p \leq 0.05)$, and only NBW subjects present a positive association between $A D I P O Q$ (assay 2) DNA methylation and total $\mathrm{BF} \%(p=0.002)$.

We further evaluated the effect of adiposity on baseline adipokine plasma levels (after $12 \mathrm{~h}$ fasting). In both groups, positive correlations were found between $\mathrm{p}$ - leptin levels and $\mathrm{BMI}$ or $\mathrm{BF} \%$, with the strongest associations observed in the NBW group for all variables (Table 2). BMI and BF\% showed significant negative associations to p-adiponectin in the NBW group and in both groups combined $(p \leq 0.005)$ (Table 2).

\section{Discussion}

To the best of our knowledge, fasting as an intervention has not previously been investigated with regard to effects on DNA methylation changes, either in animals or in humans. This study shows that the promoter DNA methylation of two metabolically important adipokine genes, $L E P$ and $A D I P O Q$, are affected by $36 \mathrm{~h}$ fasting in SAT only in NBW subjects and not LBW subjects.
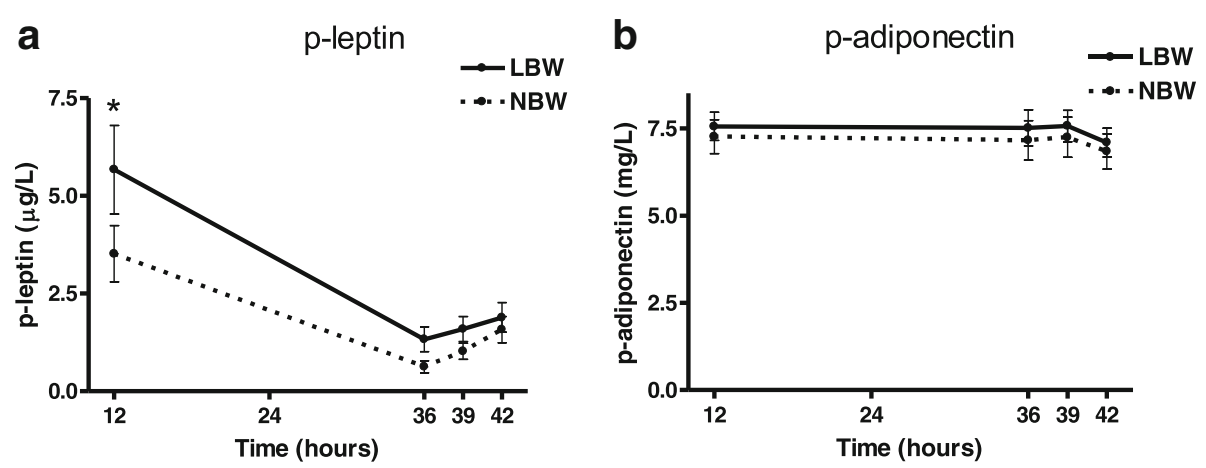

Fig. 6 P-leptin (a) and p-adiponectin (b) levels before and after $36 \mathrm{~h}$ fasting in LBW and NBW subjects. N=21 LBW, 18 NBW. Data are means \pm SEM. p-leptin levels were significantly higher among LBW subjects after $12 \mathrm{~h}$ of fasting (overnight fast) ( $p=0.05)$. A threefold decrease of p-leptin levels $(p<0.0001)$ was observed after fasting, with LBW subjects still characterized with non-significant higher $p$-leptin compared to the NBW subjects. $p$-leptin levels were also significantly different regarding the slope of the curve between the two groups $(p=0.05)$ 


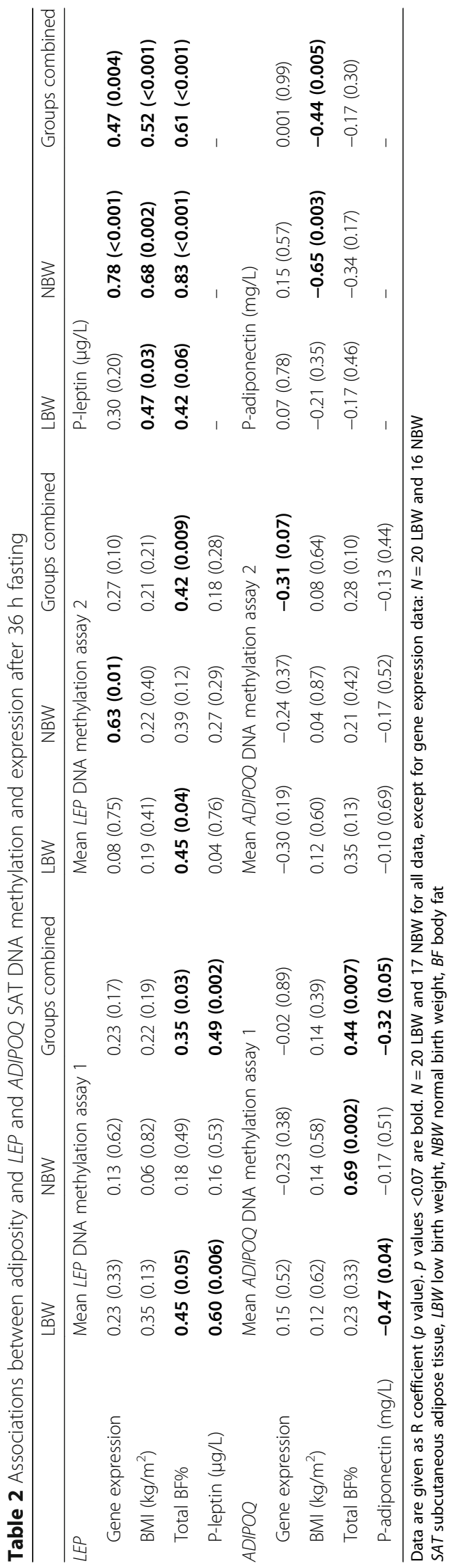


Furthermore, we show that LBW subjects have higher baseline methylation degree (after overnight fast) of both gene promoters investigated. However, our results do not support that the promoter $L E P$ and $A D I P O Q$ DNA methylation degree is directly involved in regulating gene expression under a short-term fasting intervention.

The literature investigating effects of nutritional challenges on DNA methylation in humans is limited and includes studies addressing effects of high-calorie diets [6-9]. We have previously found that LBW subjects, when undergoing a high-fat feeding, exhibit less changeability in muscle tissue DNA methylation than matched NBW controls [33]. Together with our current findings showing that only NBW subjects increase DNA methylation with fasting, it leads us to speculate that LBW subjects may be more inflexible in altering the DNA methylation status when metabolically challenged. The extent to which such metabolic inflexibility in terms of acute regulation of DNA methylation may contribute to an increased risk of metabolic disease in LBW subjects remains uncertain.

The shown changes in DNA methylation among NBW subjects occurred mostly at CpG sites located closer to the transcription start site, which was particularly prominent in the $L E P$ promoter. These results suggest that the proximal $L E P$ promoter region including the TATA box $(-30$ to -25$)$ and a transcription factor-binding site for CCAAT-enhancer-binding proteins (C/EBP) (covering CpG -51), which previously was shown to be important for regulation of gene expression in rat adipocytes [34], is more receptive to changes and might be an important region in epigenetic regulation. With respect to the observed significant changes in DNA methylation, it cannot be excluded that short-term diet or fastinginduced methylation changes, in contrast to long-term and more constitutive methylation changes, may represent some beneficial cellular effects as a part of a normal physiological response to diet changes. For example, short-term, fasting-induced methylation (and potentially gene expression) changes of $L E P$ could relate to a feedback mechanism to decrease the inhibiting effects of leptin on appetite and stimulate the subject to seek refeeding to compensate for the decreased nutrient supply. Brøns et al. demonstrated that when subjected to a 5-day high-fat diet, LBW subjects in contrast to NBW subjects did not increase p-leptin levels [26]. The lacking p-leptin response to high-fat diet may contribute to a relatively lower induction of satiety in LBW subjects. In the current study, we found a higher baseline level of pleptin among LBW subjects, which also may affect satiety among the LBW men. Moreover, p-leptin decreased with fasting in both birth weight groups.

Despite the decrease in p-leptin with fasting, which is in agreement with previous findings in fasting humans and animals [35-37], we found no effect of fasting on
LEP gene expression. Epigenetic influences on gene expression have in several studies been proposed to be involved in the pathogenesis of insulin resistance and T2D [4, 10-12, 38, 39]. Indeed LEP gene expression has been shown to be switched on by demethylation of specific CpG sites located in the proximal LEP promoter, during the differentiation of adipocytes [30]. Inspired by this study, we recently examined $L E P$ DNA methylation in differentiating adipocytes isolated from LBW and NBW subjects, and found an increased LEP DNA methylation and a decreased expression in mature adipocytes from LBW subjects compared to NBW subjects, further reinforcing the hypothesis that LBW subjects are less capable of regulating leptin secretion [40]. The decreased secretion of leptin in the differentiated adipocytes is not consistent with the increased baseline levels of p-leptin among the LBW men described in the present work, but could be explained by an intrinsic functional impairment in LBW adipocytes, causing a reduced leptin secretion. This may be compensated by an increased adiposity in vivo resulting in increased p-leptin levels. In our current study, no significant differences were found in $\mathrm{BMI}$ and $\mathrm{BF} \%$, but indeed this has been observed in previous studies of LBW subjects [6, 23].

Regarding adiponectin, previous studies have consistently reported lower circulating adiponectin levels in LBW subjects [41-43], but this association was not replicated here, possibly due to the younger age and matched study participants included in this study. An increase in $A D I P O Q$ gene expression levels was observed after fasting among LBW subjects only. This was unexpected but could relate to unknown compensatory mechanisms associated to the fasting-induced insulin resistance. Only a few studies have previously investigated the effects of fasting on $A D I P O Q$ expression and the results are of contradictory nature [44-47]. Nevertheless, we speculate that an increased degree of DNA methylation during fasting may contribute to the fasting-induced insulin resistance.

Recently BMI was reported to be associated with methylation degree in SAT, suggesting that obesity may involve pathological pathways that to some extent are epigenetically regulated [3]. In addition, Houde et al. reported that DNA methylation levels of $A D I P O Q$ in SAT were positively associated with BMI in severely obese patients [48]. In our study, total BF\% was found to be positively associated with both $L E P$ and $A D I P O Q$ promoter methylation in SAT. This further enforces that changes in SAT DNA methylation patterns are associated with obesity and could be involved in energy homeostasis, but to which degree needs to be further studied. Interestingly, LBW subjects had a higher average degree of DNA methylation in both $L E P$ and $A D I P O Q$ compared to NBW subjects, in the control study. In the same study cohort we also showed that DNA methylation of the metabolic master regulator 
PPARGC1A was higher in the LBW compared to the NBW subjects after $36 \mathrm{~h}$ fasting [27]. These results are in line with a previous finding of increased LEP promoter DNA methylation in blood from adult subjects whose mothers were exposed to famine during the periconceptional period [49].

In both birth weight groups, p-leptin level was positively associated with $\mathrm{BMI}$ and total $\mathrm{BF} \%$, corresponding well with the theory and previous studies [14, 15]. Additionally, although a significant negative correlation between plasma adiponectin levels and BMI only was observed among the NBW subjects, negative relations were shown at both body fat parameters in both groups. Still, this could indicate that LBW subjects regulate adiponectin levels differentially and not as directly associated to the amount of body fat, as NBW subjects.

There are limitations to this study, i.e., we use birth weight as a "proxy" for fetal environment. Additionally, we do not have data on the reasons for the low birth weight, e.g., maternal smoking in pregnancy or parental height and cannot exclude possible causes.

The methylation differences that we report here in SAT are slightly smaller than we observed in our previous study of PPARGC1A in muscle between LBW and NBW men after fasting (4.5\%) [27]. However, overall the magnitude of birth weight on DNA methylation seems to be modest [9]. Furthermore, a 36-h fasting intervention is a quite short time period, compared to a previous 6-month exercise study where larger effects in DNA methylation changes were observed [4]. Still, the magnitude of the methylation differences we observe in the fasting study is similar to the 5-day overfeeding study in both muscle [8] and SAT [25]. Moreover, we are only studying two genes and cannot exclude that other genes may show bigger differences in DNA methylation between the birth weight groups or with fasting. LBW is a risk factor for complex, polygenic diseases including T2D and it is well established that numerous genes with modest effect sizes in methylation changes contribute to this disease [11, 12]. However, we cannot exclude that the DNA methylation measured in our study could be affected by a stochastic variation in methylation, as earlier suggested [50].

\section{Conclusions}

A short-time metabolic fasting challenge induced small but significant changes in DNA methylation of the $A D I$ $P O Q$ and $L E P$ gene promoters in adipose tissue of young men. The findings support results from a 5-day overfeeding study, indicating that LBW subjects are less flexible in their regulation of DNA methylation degree than NBW subjects when challenged with metabolic interventions. These differential epigenetic patterns present in LBW subjects may contribute to disease development by malfunctions in the metabolically important adipose tissue.

\section{Additional files}

Additional file 1: Table S1. Primers used in amplification of the specific DNA sequences of the ADIPOQ and LEP promoter regions. Table S2. DNA methylation (\%) of CPG sites in the LEP promoter in adipose tissue. Table S3. DNA methylation (\%) of CPG sites in the ADIPOQ promoter in adipose tissue. Table S4. DNA methylation (\%) of CpG sites in the LEP promoter in adipose tissue. Table S5. DNA methylation (\%) of CpG sites in the ADIPOQ promoter in adipose tissue. (DOCX $34 \mathrm{~kb}$ )

Additional file 2: Figure S1. Influence of birth weight ( $A$ and $B$ ) and fasting ( $C$ and $D)$ on SAT PPIA gene expression levels as reference gene. A. Control study: $N=8$ LBW, 8 NBW, B. Fasting study: $N=20$ LBW, 16 NBW, comparisons by unpaired analyses between NBW and LBW subjects. C and D.: N = 8 LBW, 7 NBW, comparisons by paired analyses between control and fasting study. The standard curve principal was applied for gene expression quantification. (DOCX $27 \mathrm{~kb}$ )

\section{Acknowledgements}

We are greatly appreciative to all the young men who participated in the study. We also thank M. Modest and L.S. Koch, Steno Diabetes Center, Gentofte, for skilful assistance and technical support in the clinical experiments. Furthermore, we thank Frank Eriksson, Dept. of Biostatistics, University of Copenhagen, for assistance in conducting the mixed effects models of repeated measurements and Mona Svärdh, for assistance with q-PCR analyses.

\section{Funding}

This study was funded by the Swedish Research Council, Påhlsson Foundation, ALF, Exodiab, The Swedish Diabetes foundation, European Foundation for the study of Diabetes (EFSD), the Danish Council for Strategic Research, The Augustinus Foundation, The EU 6th Framework EXGENESIS grant, and the Danish Diabetes Academy supported by the Novo Nordisk Foundation.

\section{Availability of data and materials}

The datasets obtained and analyzed in the current study are available from the corresponding authors on reasonable request.

\section{Authors' contributions}

$\mathrm{LH}, \mathrm{SWJ}, \mathrm{AAV}$, and $\mathrm{CL}$ designed the adipokine study. SWJ, CB, and AAV designed the clinical study. SWJ and LH collected in vivo data. $\mathrm{LH}$ processed biopsies and extracted DNA and RNA. LH, LG, and EH performed DNA methylation measurements and LH performed gene expression measurements. JF performed plasma adipokine measurements. $L H, L G$, and $\mathrm{EH}$ analyzed data. LH wrote the manuscript with contribution from CB, AAV, and CL. All authors reviewed and approved the final manuscript.

\section{Competing interests}

CB and AAV are shareholders of Novo Nordisk A/S. LH, SWJ, LG, EH, JF, and $\mathrm{CL}$ declare that they have no competing interests.

\section{Consent for publication}

Not applicable.

\section{Ethics approval and consent to participate}

The study design and protocol were approved by the Ethical Committee of the Capital Region of Denmark (HD-2008-127) and conformed to the Helsinki Declaration. All participants signed a consent form after written and oral information.

\section{Publisher's Note}

Springer Nature remains neutral with regard to jurisdictional claims in published maps and institutional affiliations.

\section{Author details}

${ }^{1}$ Department of Endocrinology (Diabetes and Metabolism), Rigshospitalet, section 7652, Tagensvej 20, DK-2200 Copenhagen N, Denmark. ²Faculty of Health and Medical Sciences, University of Copenhagen, Copenhagen, Denmark. ${ }^{3}$ The Danish Diabetes Academy, Odense, Denmark. ${ }^{4}$ Steno Diabetes Center, Gentofte, Denmark. ${ }^{5}$ Epigenetics and Diabetes and Islet Cell Exocytosis, Department of Clinical Sciences, Lund University Diabetes Centre, 
Lund University, CRC, Jan Waldentröms gata 35, SE-20502 Malmö, Sweden. ${ }^{6}$ Institute of Clinical Medicine, University of Aarhus, Aarhus, Denmark. ${ }^{7}$ AstraZeneca, Mölndal, Sweden.

Received: 22 December 2016 Accepted: 12 April 2017

Published online: 21 April 2017

\section{References}

1. Hannum G, Guinney J, Zhao L, Zhang L, Hughes G, Sadda S, et al. Genomewide methylation profiles reveal quantitative views of human aging rates. Mol Cell. 2013:49:359-67.

2. Bacos K, Gillberg L, Volkov P, Olsson AH, Hansen T, Pedersen O, et al. Bloodbased biomarkers of age-associated epigenetic changes in human islets associate with insulin secretion and diabetes. Nat Commun. 2016;7:11089.

3. Rönn T, Volkov P, Gillberg L, Kokosar M, Perfilyev A, Jacobsen AL, et al. Impact of age, BMI and $\mathrm{HbA1c}$ levels on the genome-wide DNA methylation and mRNA expression patterns in human adipose tissue and identification of epigenetic biomarkers in blood. Hum. Mol. Genet. 2015;24 3792-813.

4. Nitert MD, Dayeh T, Volkov P, Elgzyri T, Hall E, Nilsson E, et al. Impact of an exercise intervention on DNA methylation in skeletal muscle from firstdegree relatives of patients with type 2 diabetes. Diabetes. 2012;61:3322-32.

5. Rönn T, Volkov P, Davegårdh C, Dayeh T, Hall E, Olsson AH, et al. A six months exercise intervention influences the genome-wide DNA methylation pattern in human adipose tissue. PLoS Genet. 2013;9:e1003572.

6. Brons $C$, Jacobsen $S$, Nilsson $E$, Ronn $T$, Jensen $C B$, Storgaard $H$, et al. Deoxyribonucleic acid methylation and gene expression of PPARGC1A in human muscle is influenced by high-fat overfeeding in a birth-weightdependent manner. J Clin Endocrinol Metab. 2010;95:3048-56.

7. Ghoshal K, Li X, Datta J, Bai S, Pogribny I, Pogribny M, et al. A folate- and methyl-deficient diet alters the expression of DNA methyltransferases and methyl CpG binding proteins involved in epigenetic gene silencing in livers of F344 rats. J Nutr. 2006:136:1522-7.

8. Jacobsen SC, Gillberg L, Bork-Jensen J, Ribel-Madsen R, Lara E, Calvanese V, et al. Young men with low birthweight exhibit decreased plasticity of genome-wide muscle DNA methylation by high-fat overfeeding. Diabetologia. 2014:57:1154-8.

9. Gillberg L, Perfilyev A, Brøns C, Thomasen M, Grunnet LG, Volkov P, et al. Adipose tissue transcriptomics and epigenomics in low birthweight men and controls: role of high-fat overfeeding. Diabetologia. 2016;59:799-812

10. Nilsson E, Jansson PA, Perfilyev A, Volkov P, Pedersen M, Svensson MK, et al. Altered DNA methylation and differential expression of genes influencing metabolism and inflammation in adipose tissue from subjects with type 2 diabetes. Diabetes. 2014:63:2962-76.

11. Nilsson E, Matte A, Perfilyev A, de Mello VD, Käkelä P, Pihlajamäki J, et al. Epigenetic alterations in human liver from subjects with type 2 diabetes in parallel with reduced folate levels. J Clin Endocrinol Metab. 2015;100:E1491-501.

12. Dayeh T, Volkov P, Salö S, Hall E, Nilsson E, Olsson AH, et al. Genome-wide DNA methylation analysis of human pancreatic islets from type 2 diabetic and non-diabetic donors identifies candidate genes that influence insulin secretion. Greally JM, editor. PLoS Genet. 2014;10:e1004160.

13. Iwaki M, Matsuda M, Maeda N, Funahashi T, Matsuzawa $Y$, Makishima M, et al. Induction of adiponectin, a fat-derived antidiabetic and antiatherogenic factor, by nuclear receptors. Diabetes. 2003;52:1655-63.

14. Friedman JM. The function of leptin in nutrition, weight, and physiology. Nutr Rev. 2002;60:S1-14.

15. Friedman JM. Leptin and the regulation of body weigh. Keio J Med. 2011;60:1-9.

16. Matsuzawa Y. Adiponectin: a key player in obesity related disorders. Curr Pharm Des. 2010;16:1896-901.

17. Horikoshi M, Beaumont RN, Day FR, Warrington NM, Kooijman MN, Fernandez-Tajes J, et al. Genome-wide associations for birth weight and correlations with adult disease. Nature. 2016;538:248-52.

18. Nomura Y, Lambertini L, Rialdi A, Lee M, Mystal EY, Grabie M, et al. Global methylation in the placenta and umbilical cord blood from pregnancies with maternal gestational diabetes, preeclampsia, and obesity. Reprod Sci. 2014;21:131-7

19. Gordon L, Joo JE, Powell JE, Ollikainen M, Novakovic B, Li X, et al. Neonatal DNA methylation profile in human twins is specified by a complex interplay between intrauterine environmental and genetic factors, subject to tissuespecific influence. Genome Res. 2012;22:1395-406.
20. Pinney SE, Jaeckle Santos $\sqcup$, Han Y, Stoffers DA, Simmons RA. Exendin-4 increases histone acetylase activity and reverses epigenetic modifications that silence Pdx1 in the intrauterine growth retarded rat. Diabetologia. 2011;54:2606-14.

21. Park JH, Stoffers DA, Nicholls RD, Simmons RA. Development of type 2 diabetes following intrauterine growth retardation in rats is associated with progressive epigenetic silencing of Pdx1. J Clin Invest. 2008;118:2316-24

22. Heijmans BT, Tobi EW, Stein AD, Putter H, Blauw GJ, Susser ES, et al. Persistent epigenetic differences associated with prenatal exposure to famine in humans. Proc Natl Acad Sci U S A. 2008;105:17046-9.

23. Ravelli AC, van der Meulen JH, Michels RP, Osmond C, Barker DJ, Hales CN, et al. Glucose tolerance in adults after prenatal exposure to famine. Lancet (London, England). 1998;351:173-7.

24. Harder T, Rodekamp E, Schellong K, Dudenhausen JW, Plagemann A. Birth weight and subsequent risk of type 2 diabetes: a meta-analysis. Am J Epidemiol. 2007:165:849-57.

25. Gillberg $L$, Jacobsen SC, Ronn T, Brons C, Vaag A. PPARGC1A DNA methylation in subcutaneous adipose tissue in low birth weight subjects-impact of 5 days of high-fat overfeeding. Metabolism. 2014;63:263-71.

26. Brøns C, Jacobsen S, Hiscock N, White A, Nilsson E, Dunger D, et al. Effects of High-Fat Overfeeding on Mitochondrial Function, Glucose and Fat Metabolism, and Adipokine Levels in low-birth-weight subjects. Am. J. Physiol. Endocrinol. Metab. 2012;302:E43-51.

27. Jørgensen SW, Brøns C, Bluck L, Hjort L, Færch K, Thankamony A, et al. Metabolic response to 36 hours of fasting in young men born small vs appropriate for gestational age. Diabetologia. 2015;58:178-87.

28. Frystyk J, Tarnow L, Hansen TK, Parving HH, Flyvbjerg A. Increased serum adiponectin levels in type 1 diabetic patients with microvascular complications. Diabetologia. 2005:48:1911-8.

29. Asferg C, Møgelvang R, Flyvbjerg A, Frystyk J, Jensen JS, Marott JL, et al. Leptin, not adiponectin, predicts hypertension in the Copenhagen City Heart Study. Am J Hypertens. 2010;23:327-33.

30. Melzner I, Scott V, Dorsch K, Fischer P, Wabitsch M, Bruderlein S, et al. Leptin gene expression in human preadipocytes is switched on by maturationinduced demethylation of distinct CpGs in its proximal promoter. J Biol Chem. 2002;277:45420-7.

31. Kita A, Yamasaki H, Kuwahara H, Moriuchi A, Fukushima K, Kobayashi M, et al. Identification of the promoter region required for human adiponectin gene transcription: association with CCAAT/enhancer binding protein-beta and tumor necrosis factor-alpha. Biochem Biophys Res Commun. 2005;331:484-90.

32. Segawa K, Matsuda M, Fukuhara A, Morita K, Okuno Y, Komuro R, et al. Identification of a novel distal enhancer in human adiponectin gene. J Endocrinol. 2009;200:107-16.

33. Jacobsen SC, Brøns C, Bork-Jensen J, Ribel-Madsen R, Yang B, Lara E, et al. Effects of short-term high-fat overfeeding on genome-wide DNA methylation in the skeletal muscle of healthy young men. Diabetologia. 2012;55:3341-9.

34. Mason MM, He Y, Chen H, Quon MJ, Reitman M. Regulation of leptin promoter function by Sp1, C/EBP, and a novel factor. Endocrinology. 1998; 139:1013-22.

35. Kristensen K, Pedersen SB, Fisker S, Norrelund H, Rosenfalck AM, Jorgensen $\mathrm{O}$, et al. Serum leptin levels and leptin expression in growth hormone $(\mathrm{GH})$-deficient and healthy adults: influence of $\mathrm{GH}$ treatment, gender, and fasting. Metabolism. 1998:47:1514-9.

36. Faulconnier $Y$, Chilliard $Y$, Torbati MB, Leroux $C$. The transcriptomic profiles of adipose tissues are modified by feed deprivation in lactating goats. Comp. Biochem. Physiol. Part D. Genomics Proteomics. 2011;6:139-49.

37. Lkhagvadorj S, Qu L, Cai W, Couture OP, Barb CR, Hausman GJ, et al. Gene expression profiling of the short-term adaptive response to acute caloric restriction in liver and adipose tissues of pigs differing in feed efficiency. Am J Physiol Regul Integr Comp Physiol. 2010;298:R494-507.

38. Ling C, Rönn T. Epigenetic markers to further understand insulin resistance. Diabetologia. 2016:59:2295-7.

39. Arner $P$, Sahlqvist A-S, Sinha I, Xu H, Yao X, Waterworth D, et al. Erratum to: The epigenetic signature of systemic insulin resistance in obese women. Diabetologia. 2016;59:2728

40. Schultz NS, Broholm C, Gillberg L, Mortensen B, Jørgensen SW, Schultz HS, et al. Impaired leptin gene expression and release in cultured preadipocytes isolated from individuals born with low birth weight. Diabetes. 2014;63:111-21.

41. Jaquet D, Deghmoun S, Chevenne D, Czernichow P, Levy-Marchal C. Low serum adiponectin levels in subjects born small for gestational age: impact on insulin sensitivity. Int J Obes. 2006;30:83-7. 
42. Storgaard H, Poulsen P, Ling C, Groop L, Vaag AA. Relationships of plasma adiponectin level and adiponectin receptors 1 and 2 gene expression to insulin sensitivity and glucose and fat metabolism in monozygotic and dizygotic twins. J Clin Endocrinol Metab. 2007;92:2835-9.

43. Mazaki-Tovi S, Kanety H, Pariente C, Hemi R, Yinon Y, Wiser A, et al. Adiponectin and leptin concentrations in dichorionic twins with discordant and concordant growth. J Clin Endocrinol Metab. 2009;94:892-8.

44. Gui Y, Silha JV, Mishra S, Murphy $\sqcup$. Changes in adipokine expression during food deprivation in the mouse and the relationship to fasting-induced insulin resistance. Can J Physiol Pharmacol. 2003;81:979-85.

45. Maddineni S, Metzger S, Ocon O, Hendricks III G, Ramachandran R. Adiponectin gene is expressed in multiple tissues in the chicken: food deprivation influences adiponectin messenger ribonucleic acid expression. Endocrinology. 2005;146:4250-6.

46. Romero MM, Fernandez-Lopez JA, Esteve M, Alemany M. Different modulation by dietary restriction of adipokine expression in white adipose tissue sites in the rat. Cardiovasc Diabetol. 2009;8:42.

47. Tahmoorespur M, Ghazanfari S, Nobari K. Evaluation of adiponectin gene expression in the abdominal adipose tissue of broiler chickens: feed restriction, dietary energy, and protein influences adiponectin messenger ribonucleic acid expression. Poult Sci. 2010;89:2092-100.

48. Houde A-A, Légaré C, Biron S, Lescelleur O, Biertho L, Marceau S, et al. Leptin and adiponectin DNA methylation levels in adipose tissues and blood cells are associated with BMI, waist girth and LDL-cholesterol levels in severely obese men and women. BMC Med Genet. 2015;16:29.

49. Tobi EW, Lumey LH, Talens RP, Kremer D, Putter H, Stein AD, et al. DNA methylation differences after exposure to prenatal famine are common and timing- and sex-specific. Hum Mol Genet. 2009;18:4046-53.

50. Leung C, Breton S, Angers B. Facing environmental predictability with different sources of epigenetic variation. Ecol Evol. 2016;6:5234-45.

\section{Submit your next manuscript to BioMed Central and we will help you at every step:}

- We accept pre-submission inquiries

- Our selector tool helps you to find the most relevant journal

- We provide round the clock customer support

- Convenient online submission

- Thorough peer review

- Inclusion in PubMed and all major indexing services

- Maximum visibility for your research

Submit your manuscript at www.biomedcentral.com/submit 